\title{
Surgical Repair of Pectoralis Muscle Rupture Following Sport/Exercise Injuries: Case Series
}

\section{Athar MS*, Ashwood N and Hamlet M \\ Consultant Orthopaedic surgeon, Queens Hospital, UK}

*Corresponding author: M Sajjad Athar, Consultant Orthopaedic surgeon, Queens Hospital, Burton, 12 green valley drive Burton on Trent DE13 0QS UK, Tel: 07919263787; E-mail: msathar@hotmail.com

\section{Research Article}

Volume 1 Issue 1

Received Date: January 18, 2017

Published Date: February 15, 2017

DOI: $10.23880 /$ mjccs-16000101

\section{Abstract}

Rupture of the Pectoralis muscle tendon is usually rare. And when it does happen, Sports or exercises are most often the culprit. An abducted, extended and externally rotated shoulder is weak and adding tension to it, as happens during a bench press or throwing a ball, is likely to tear off the Pectoral tendon. Sites recognized are: At Tendon attachment, Musculo-tendinous junction and Muscle belly.

This is a retrospective case review of three cases of Pectoral tear that underwent Open Surgical repair with fibre-tape and Pec-buttons. No major complications (hematoma, prosthesis failure, persistent pain) witnessed thus far in early postoperative phase (3 months). Notably, MRI imaging did not show any tear in two of the cases despite strong clinical suspicion, prior to surgery. This review has led to the conclusion that, surgical repair for Pectoral tear is a very effective method of treatment, for both complete \& incomplete rupture. And MRI imaging, although very sensitive and useful for soft tissues, may not be specific \& is best used as an adjunct to aid the Clinical diagnosis only.

Keywords: Pectoralis Muscle Rupture; Pectoral tendon; Musculo-tendinous junction; Muscle belly; Surgical repair

\section{Introduction}

Rupture of the Pectoralis muscle tendon is usually rare. And when it does happen, Sports or exercises are most often the culprit. An abducted, extended and externally rotated shoulder is weak and adding tension to it, as happens during a bench press or throwing a ball, is the most likely mechanism to tear off the Pectoral tendon. Sites recognised are: At tendon attachment, Musculotendinous junction and Muscle belly 2012, El Maraghy A [1]. Patients often present with pain, bruising over medial arm and chest deformity with restricted range of shoulder movement. Surgical repair for tear is a very effective method of treatment, especially in cases of complete rupture.

\section{Background}

The powerful Pectoralis muscle is responsible for the adduction, external rotation and flexion of the shoulder joint. Anatomically, it is known to have an upper, Clavicular head and a lower sternal head. Fibers emerge towards the Lateral lip of Bicipital groove of Humerus in a rather unusual pattern, as the Clavicular and upper sternal fibers insert distally and the lower sternal and abdominal fibers cross the former and insert proximally. 


\section{Medical Journal of Clinical Trials \& Case Studies}

Currently, ruptures of the Pectoralis muscle tendon are on the rise. This frequently happens in sports like weight lifting, Rugby, American football and Cricket. The patient presents with a history of severe sharp pain, with or without a 'snap' at the time of injury, followed by painful and reduced range of movement, localized swelling and ecchymosis over the shoulder. When examined, there is a classic 'bunched-up' deformity over this muscle region as the muscle becomes retracted, and leaves a thin anterior axillary fold or sulcus at the Delto-pectoral groove. Specific muscular tests show weakness on adduction and internal rotation of the arm.

It was first described by Patissierin 1822, followed by Letenneur in 1861. Between 1822 and 2010, 365 cases of PM injury were published $(75 \%$ occurred in the last 20 years). The vast majority resulted from an indirect trauma [2]. Various authors have attempted to grade these injuries in order to aid in the diagnosis, treatment and rehabilitation. In 2012, El Maraghy A [1] came forth with a new classification system based on a) time of injury, (acute or chronic), b) the anatomic location (at the muscleorigin or muscle belly, at or between the musculotendinous junction and the tendinous insertion, or bony avulsion). Most commonly the Pectoralis major muscle tendon ruptures off the Humerus bone.

Then management technique we describe is the "Fibertape and Pec Button repair technique" [6]. Firstly, exposure of the tendons via an incision over anterior axillary fold is done followed by fiber tape suturing of the medial end. Then, on the Humeral surface pilot holes are drilled with a $3.7 \mathrm{~mm}$ drill bit and Pec Buttons are threaded with fiber tape and docked into the Humerus. With tension-slide technique the tendon is re-attached.

Here we discuss three cases of Pectoralis muscle rupture and the subsequent management.

\section{Case 1}

A 21 years young man injured his Right shoulder while bowling in cricket. He was initially, treated for a SLAP tear. He underwent Arthroscopic Biceps tenodesis followed by shoulder Physiotherapy for over 21 months. Then in an attempt to revive his bowling career, he injured his shoulder again.

On clinical examination, bruise could be seen in the arm medially and with tenderness in pectoral area. Pectoralis muscle injury was suspected and MRI scan was asked for. However, the MRI-Arthrogram did not show obvious tear. Patient was followed up for a month, and on re- examination an abnormal contracture of the muscle was found (Stress test), which confirmed the suspicion, despite the normal MRI result.

Surgery: Direct observation revealed scarring of the inferior pectoral fibres which were released. Fiber-tape sutures through the tendon end attached to Arthrex Pec. Buttons, and fixed with those through tunnels in the Humerus just lateral to the Biceps tendon.

At present rehabilitation is on-going without any complications.

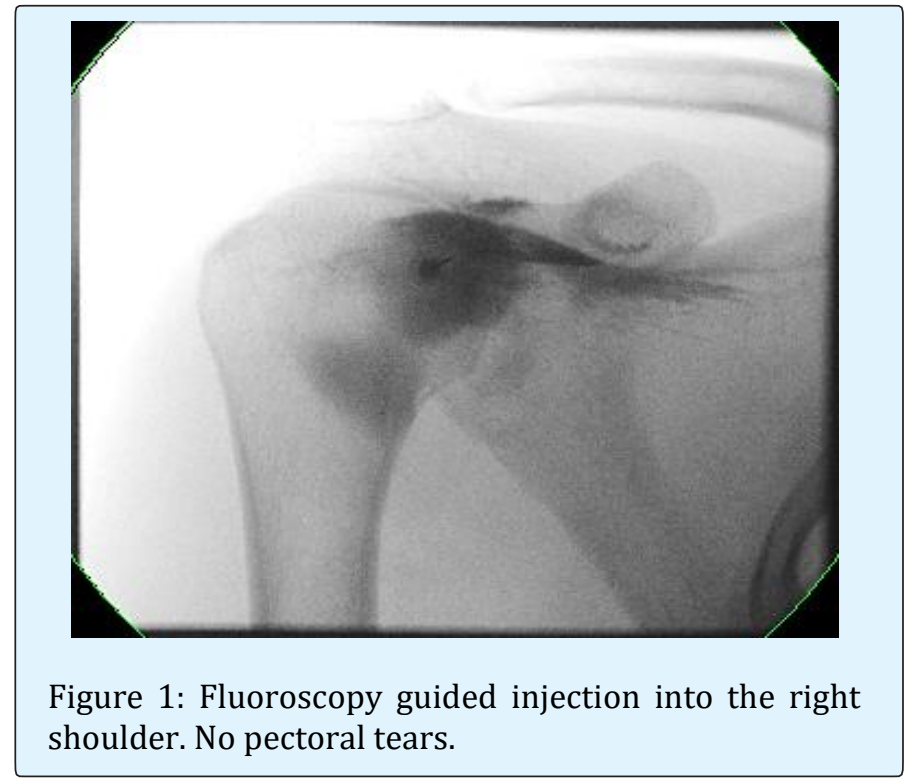

\section{Case 2}

A 22 years young man presented with complaints of persisting pain and deformity over his Left upper chest. He had felt sharp pain/snap over the upper and outer left chest region while performing bench press, 6 weeks prior.

On examination one could notice loss of pectoral muscle contour laterally and quite significant bulking of Pectoral muscle with resisted shoulder adduction. Loss of power was noted in adduction and medial rotation. Additionally, Rotator cuff injury was deemed improbable.

MRI scan of the muscle at 2 months after the injury did not show any obvious rupture, in contrast to the clinical picture. However, the possibility of inferior tendon displacement underneath the clavicle was recognised and following a discussion with the patient, surgery was opted for.

Surgery: Open Left Pectoralis repair under Regional block. Direct observation revealed Inferior bundle rupture 


\section{Medical Journal of Clinical Trials \& Case Studies}

of the pectoral tendon. It was tied to the Humerus with fiber-tape and button. At present; patient does complain of soreness, but steady recovery with physiotherapy, witnessed.
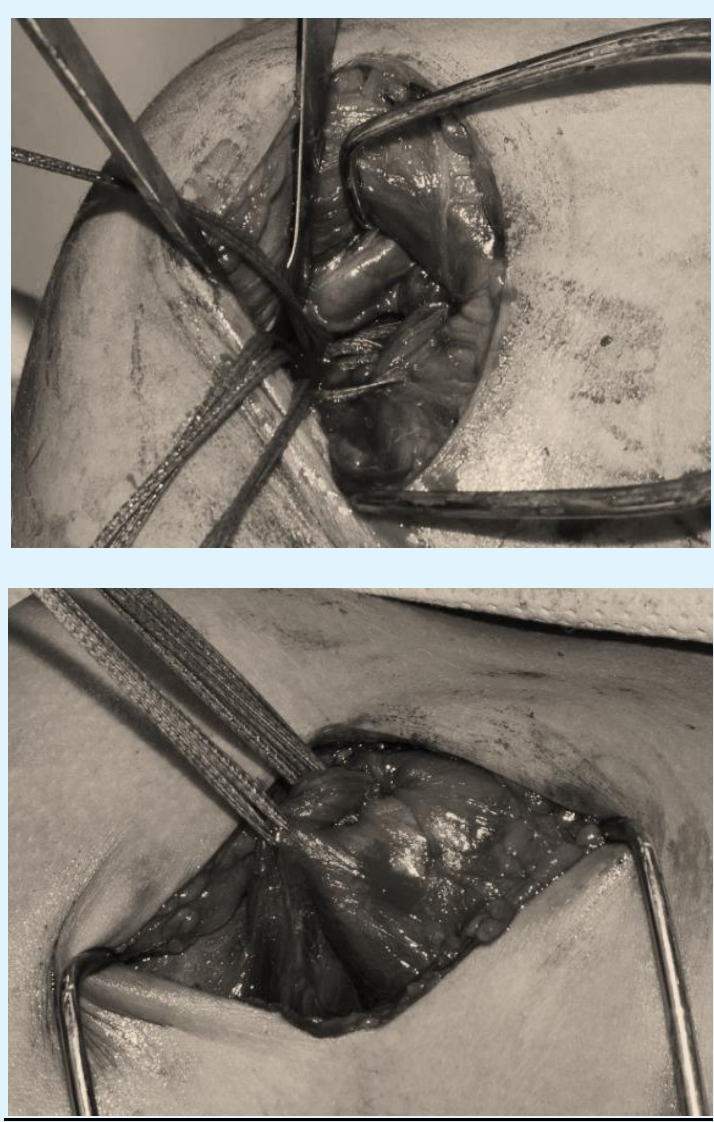

Figure 2: Use of Fiber-tape Sutures to tie the pectoral tendon to humerus.

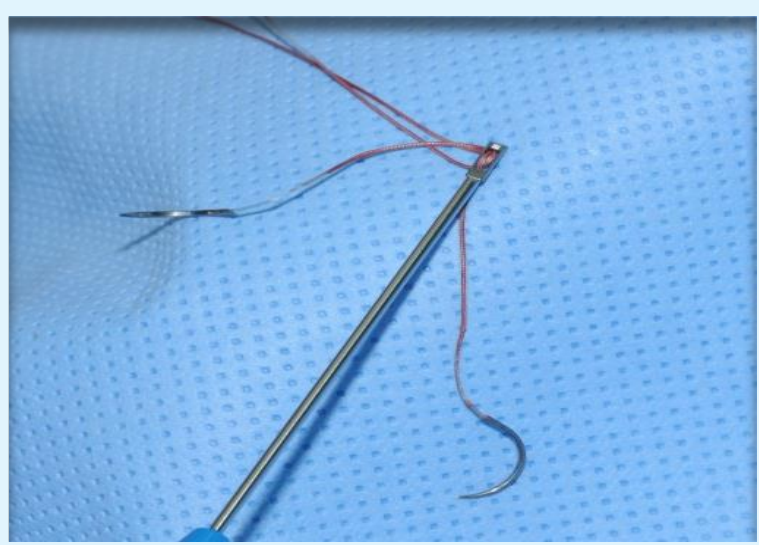

Figure 3: Fibre-tape Sutures.

\section{Case 3}

A 25 years young man presented with left shoulder injury while climbing Monkey bars and persistent pain for 2 months. Examination on this case also revealed an abnormal contour of inferior part of muscle suggesting Musculo-tendinous tear.

MRI revealed rupture of the musculo-tendinous junction of the sternal head of the left Pectoralis major muscle with soft tissue oedema and retraction of $4 \mathrm{~cm}$.

Surgery: On table findings confirmed the MRI pictures. Open repair started. The scarred up pectoral head adherent to inferior surface were freed and Fiber Tape was used tie the parachuted fibers of Pectoralis major to the Humerus, secured by Pec buttons.

At present: The patient was advised to avoid heavy loading for 3 months atleast and slow gradual recovery with physiotherapy ensued.

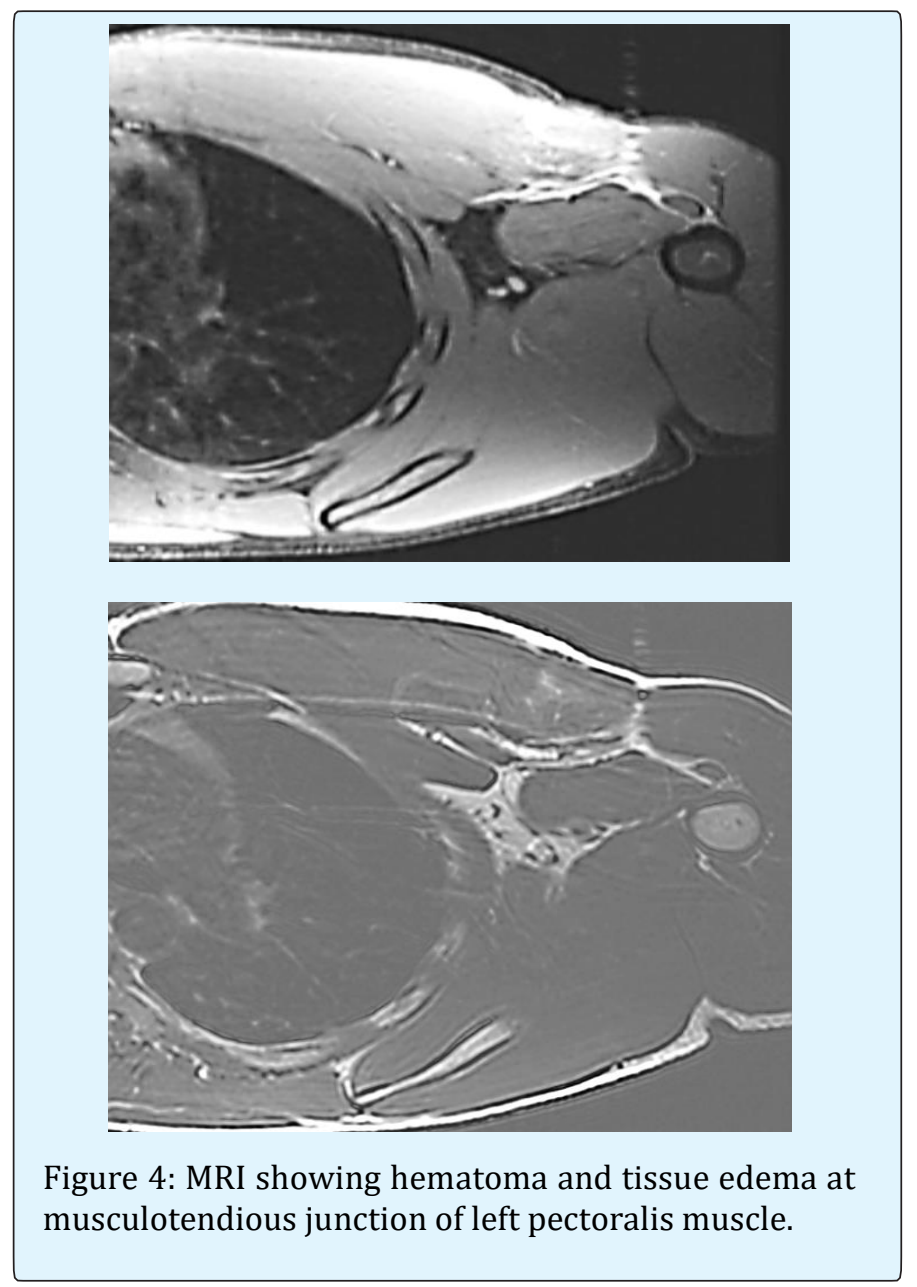




\section{Medical Journal of Clinical Trials \& Case Studies}

\section{Comparative Results}

\begin{tabular}{|c|c|c|c|}
\hline & $\begin{array}{c}\text { Case } 1 \\
(21 \mathrm{y}, \mathrm{m})\end{array}$ & $\begin{array}{c}\text { Case } 2 \\
(22 y, m)\end{array}$ & $\begin{array}{c}\text { Case } 3 \\
(25 y, m)\end{array}$ \\
\hline Mode of Injury & $\begin{array}{l}\text { - Injury x2 of Right shoulder } \\
\text { during bowling in Cricket. } \\
\text { - Pain \& restricted movement }\end{array}$ & $\begin{array}{c}\text { - Left anterior sharp Chest } \\
\text { pain, during Bench press } \\
\text { - Persisting pain for } 6 \\
\text { weeks, } \\
\text { with deformity } \\
\end{array}$ & $\begin{array}{l}\text {-Injured while climbing } \\
\text { Monkey bars; } \\
\text { - Persisting pain for } 2 \\
\text { months }\end{array}$ \\
\hline Clinical Findings & $\begin{array}{l}\text { - Bruise over anterior } \\
\text { shoulder - abnormal } \\
\text { contracture of the Pectoralis } \\
\text { muscle during pushing } \\
\text { movement. }\end{array}$ & $\begin{array}{l}\text { - Bulking deformity of the } \\
\text { muscle ; } \\
\text { - Loss of Power in } \\
\text { adduction and medial } \\
\text { rotation }\end{array}$ & $\begin{array}{l}\text { - Abnormal contour of } \\
\text { the inferior muscle fibres, } \\
\text { during contraction. }\end{array}$ \\
\hline MRI & $\begin{array}{l}\text { At } 14 \text { days from injury } \\
\text { No Obvious tear }\end{array}$ & $\begin{array}{l}\text { At } 60 \text { days from injury } \\
\text { No Obvious tear }\end{array}$ & $\begin{array}{c}\text { Musculotendinous } \\
\text { junction tears of Sternal } \\
\text { head. }\end{array}$ \\
\hline $\begin{array}{c}\text { On Table Findings } \\
\text { Management - Open } \\
\text { Repair Under Regional } \\
\text { Block }\end{array}$ & $\begin{array}{l}\text {-Pectoral tendon avulsion } \\
\text { from Humerus. } \\
\text { - Fiber-tape sutures through } \\
\text { tendon and Pec } \\
\text { buttons.@Arthrex }\end{array}$ & $\begin{array}{l}\text { - Inferior tendon-bundle } \\
\text { rupture } \\
\text { - Tendon tied to Humerus } \\
\text { with fiber-tape and Pec } \\
\text { button. } \\
\end{array}$ & $\begin{array}{l}\text { - Musculo-tendinous } \\
\text { rupture } \\
\text {-Fiber tape and } \\
\text { Pecbutton used to tie } \\
\text { tendon to Humerus. } \\
\end{array}$ \\
\hline
\end{tabular}

\section{Discussion}

These cases are in early post-operative phase (3 months), and under regular follow-up. Two of the cases show very good recovery with progressive physiotherapy - minimal pain for normal activities. Although the third patient is struggling with soreness, it has shown a decreasing trend. This evidence is consistent with separate studies done by Aarima et al. [2] and Bak et al. [3]. Hanna CM, in 2002 [10], reported 21 patients with complete Pectoralis muscle tear, of which ten surgically treated patients showed $41-43 \%$ greater recovery of work performed and peak torque when tested with a Kincom Isokinetic Dynamometer, than conservative management. Furthermore, no complications such as Post op bleeding, infection or joint stiffness has been found in any of the cases.

We cannot help but mention that, amongst the three, MRI failed to demonstrate ruptures in two cases. This contradicts the finding of Connell et al. [4] who published an article in 1998, based on a case series of 15 patients similar injuries and concluded that MRI is "the" imaging technique for evaluation of such injuries. Additionally, according to Ohashi et al. [5] the imaging modality had very good surgical correlations. Despite such strong evidences however, the disparity between the correct clinical findings and incorrect MRI findings in two of our cases cannot be overlooked.

\section{Conclusion}

Early surgical repair followed by physiotherapy can allow $80-90 \%$ of functionality and return to normality, compared to $60-70 \%$ from conservative management [2]. Even in partial tears, surgery seems worthwhile, particularly to restore contour. MRI appears to have poor specificity in delineating the exact site of rupture \& occasionally can be unhelpful. It serves as an excellent adjunct, but cannot substitute Clinical examination.

\section{References}

1. ElMaraghy AW, Devereaux MW (2012) A systematic review and comprehensive classification of pectoralis major tears. J Shoulder Elbow Surg 21(3): 412-422.

2. Aarimaa V, Rantanen J, Heikkila J, Helttula I, Orava S (2004) Rupture of the pectoralis major muscle. Am J Sports Med 32(5): 1256-1262.

3. Butcher JD, Siekanowicz A, Pettrone F (1996) 


\section{Medical Journal of Clinical Trials \& Case Studies}

Pectoralis major rupture: Ensuring accurate diagnosis and effective rehabilitation. Physician Sportsmed 24(3): 37-44.

4. Bak K, Cameron EA, Henderson IJP (2000) Rupture of the pectoralis major: a meta-analysis of 112 cases. Knee Surg Sports Traumatol Arthrosc 8(2): 113-119.

5. Hanna CM, Glenny AB, Stanley SN, Caughey MA (2001) Pectoralis major tears: comparison of surgical and conservative treatment. Br J Sports Med 35(3): 202-206.

6. Connell DA, Potter HG, Sherman MF, Wickiewicz TL (1999) Injuries of the Pectoralis Major Muscle: Evaluation with MR Imaging. Radiology 210(3): 785791.

7. Ohashi K, El-Khoury GY, Albright JP, Tearse DS (1996) MRI of complete rupture of the pectoralis major muscle. Skeletal Radiol 25(7): 625-628.

8. Rijnberg WJ, van Linge B (1993) Rupture of the pectoralis major muscle in body-builders. Arch Orthop Trauma Surg 112(2): 104-105.

9. Metzger PD, Bailey JR, Filler RD, Waltz RA, Provencher MT, et al. (2012) Pectoralis Major Muscle
Rupture Repair: Technique Using Unicortical Buttons. Arthrosc Tech 1(1): 119-125.

10. Quinlan JF, Molloy M, Hurson BJ (2002) Case Report: Pectoralis major tendon ruptures: when to operate. Br J Sports Med 36: 226-228.

11. Kretzler $H H$, Richardson $A B$ (1989) Rupture of the pectoralis major muscle. Am J Sports Med 17(4): 453458.

12. Scott W Wolfe, Thomas L Wickiewicz, John $\mathrm{T}$ Cavanaugh (1992) Ruptures of the pectoralis major muscle: An anatomic and clinical analysis. Am J Sports Med 20(5): 587-593.

13. Kakwani RG, Matthews JJ, Kumar KM, Pimpalnerkar A, Mohtadi N (2007) Rupture of the pectoralis major muscle: Surgical treatment in athletes. Int Orthop 31(2): 159-163.

14. Schepsis AA, Grafe MW, Jones HP, Lemos MJ (2000) Rupture of the pectoralis major muscle. Outcome after repair of acute and chronic injuries. Am J Sports Med 28(1): 9-15. 